\title{
Updates in ASIA Examination: Sensory Examination
}

\author{
Ebru YILMAZ YALÇINKAYA \\ Istanbul Physical Medicine and Rehabilitation Training and Research Hospital, Istanbul, Turkey
}

\begin{abstract}
Knowledge of the American Spinal Cord Association neurological examination standards is necessary to communicate in colloquial and standard scientific language. The basic aim of this review is to explain the up-to-date required sensory examination components of ASIA neurologic examination. The second aim is to review optional sensory examination (that is not requiered to define neurologic level) and neurologic level and sensory examination in pediatric patients.

Keywords: Spinal cord injury, sensory examination, ASIA
\end{abstract}

\section{Introduction}

The International Standards for Neurological Classification of Spinal Cord Injury, which was developed by the American Spinal Injury Association (ASIA), is most commonly used and has the highest sensitivity the existing scales $(1,2)$.

The two main components of the neurological examination are sensory and motor examinations. As a result of this examination, the degree of the sensory/motor/ neurological degrees and the completeness of the injury are evaluated, and sensory and motor scores are obtained (3).

Except rectal examination that is done at the side-lying position, all evaluations are always performed at the supine position during examinations (3-5). In case of spinal instability in the early period, either the spinal column should be moved to sideways as a whole or a short examination in the supine position should be done. Any key sensory points or key muscles not evaluated because of any reason (burn, cast, amputation, or absence of feeling on the patient's face) should be named as not testable (NT) $(1,3)$.

\section{Sensory Examination}

There are eight nerve roots in the cervical spine. $\mathrm{C} 1-\mathrm{C} 7$ roots are originated from the associated vertebrae, and $\mathrm{C} 1$ is originated from the posterior of the skull; there is no $\mathrm{C} 1$ sensory area, namely dermatome, which can be tested in accordance with the ASIA international examination standards (1).

The skin area innervated by a sensory axon in each segmental nerve (root) is called dermatome.

\section{Necessary Tests}

In the part of necessary tests for the sensory examination, pinpricking (differentiation between sharp and blunt) and lighttouch sensations are completed with the evaluation of 28 specific dermatome areas (C2-S4-5), which are also known as key sensation points. There are two reasons for the Committee to recommend these points. First, each key sensory point exists in the dermatome body map that is mentioned in many wellknown anatomy references. Second, because these key sensory points are related to anatomically distinctive bone structures, they are safe and easy to detect, and this ensures the reliability between the groups $(3,6)$. 
Sensory examination is performed on 28 dermatomes and 56 key points. These points can be easily localized according to their relation with anatomical bone indicators (Table 1) (5). Detailed pictures of dermatomes and indicators can be inspected at the $4^{\text {th }}$ reference.

Examination is done from the cranial to the caudal, and the score is recorded in the ASIA international standard examination card (5).

\section{Light Touch}

Light-touch sensation is performed on 28 dermatomes. A piece of cotton, cotton-wrapped stick, fingertip, or paper napkin can be used. The viewed object should be noted. A piece of cotton is touched to the cheek of a patient, and the dermatomes are compared with the cheek of a patient with the eyes closed. The area touched by the cotton should not be $>1 \mathrm{~cm}(1,3,5)$. The procedure is explained to the patient. Cotton is lightly touched to the cheek. The patient is asked the following questions (5):
- "Indicate when you feel my touch"

- "Is the feeling of my touch same as the feeling on your cheek or different?"

Scoring:

- 0 : Patient is unable to accurately and reliably describe the touching sensation.

- 1: Patient is able to accurately identify touch but states that it is different from the feeling of touch on the cheek (more, less, etc.).

- 2: Normal patient is able to correctly identify the touch and states that it is the same with the cheek.

NT: Unable to be tested for various reasons. If a key point is unable to be evaluated for any reason (cast, laceration, or amputation), another key point in the same dermatome can be evaluated and recorded $(1,3,5)$.

\section{Table 1. Key points of dermatomes for sensory examination}

Dermatome-Key Points

C2- At least $1 \mathrm{~cm}$ lateral to the occipital protuberance (as alternative, $3 \mathrm{~cm}$ to the back of the ear)

C3- Supraclavicular fossa (behind clavicle) and midclavicular line

C4- On the acromioclavicular joint

C5- Side of antecubital fossa lateral (radial) (proximal to the elbow line)

C6- Thumb, dorsal aspect, and proximal phalanx

C7- Middle finger, dorsal aspect, and proximal phalanx

C8- Small finger, dorsal aspect, and proximal phalanx

T1- Antecubital fossa medial (ulnar) side and proximal to the humerus medial epicondyle

T2- Axilla apex

T3- On the midclavicular line and in the $3^{\text {rd }}$ intercostal space (IS); determined by palpating the 3rd costa and the space just below that 3. IS*

T4- On the midclavicular line and in the $4^{\text {th }}$ IS (level of the nipple)

T5- On the midclavicular line and in the $5^{\text {th }}$ IS (middle point of T4 and T6)

T6- On the midclavicular line and in the $6^{\text {th }}$ IS (xiphisternum level)

T7- On the midclavicular line and in the $7^{\text {th }}$ IS (middle point of T6 and T8)

T8- On the midclavicular line and in the $8^{\text {th }}$ IS (middle point of T6 and T10)

T9- On the midclavicular line and in the $9^{\text {th }}$ IS (middle point of T8 and T10)

T10- On the midclavicular line and in the $10^{\text {th }}$ IS (umbilicus)

T11- On the midclavicular line and in the $11^{\text {th }}$ IS (middle point of T10 and T12)

T12- On the midclavicular line and the middle point of the inguinal ligament

L1 - Middle of the distance between T12 and L2 sensory key points

L2- In the anterior-medial femur, the middle point of the line between the middle point of the inguinal ligament (T12) and the medial femoral condyle

L3- Above the medial condyle on the knee

L4- Medial malleolus

L5- $3^{\text {rd }}$ metatarsophalangeal joint on the dorsum of the foot

S1- Lateral heel (calcaneus)

S2- Middle point of the popliteal fossa

S3- Ischial tuberosity or infragluteal fold

S4-5- Perianal region, $<1 \mathrm{~cm}$ lateral to the mucocutaneous junction (a single level is accepted) 


\section{Pin-pricking Sensation}

It is performed using the sharp and blunt tip of a safety pin. By touching on the face of a patient, sharp and blunt sensations are defined. Afterwards, dermatomes are tested with a patient's eyes closed $(1,3)$.

The following questions are asked to patient:

- Is it sharp or blunt?

- Is the feeling same with what you feel on your face?

Scoring

0 : Patient is unable to differentiate the sensations of sharpness or bluntness.

1: Impaired: Patient is able to differentiate different tips of the safety pin but states that there is a difference between the evaluated point and the face (more or less feeling).

2: Normal: Patient is able to completely differentiate the sharp and blunt tips of the safety pin and states that there is no difference between the evaluated and reference points (the face).

NT: Not tested/evaluated for various reasons

- In case of suspected situations, 8 out of 10 is accepted as normal (5).

- If the patient is unable to identify sharpness or bluntness but is able to feel the touch, the pin-pricking sensation score is 0 (5).

- If the patient identifies both tips as blunt while trying to differentiate the sharp tip from the blunt tip, the score is 0 (5).

- $\quad$ Errors can be made while testing T3. The dermatome C4 may decline to the chest wall in the anterior and be confused with T3. In this case, if T1-T2 and T4 are evaluated as 0, T3 can also be evaluated as 0 .

- Sensory level is determined with this examination. Sensory level is the most caudal segment in which the pin-pricking and superficial-touch sensations are strong. Pin-pricking and superficial-touch sensation levels in the right and left sides can be defined in a more detailed way $(3,5)$.

- It has been reported that the protection of pin-pricking sensation is related to a good prognosis (6).

\section{Optional}

Not required but optional sensory examination in determining neurological level.

- Joint motion and position sense

- Deep pressure/deep pain

Why do we evaluate or not evaluate the optional sensation? It is optional because:

1. It can be related to the functional condition of the tested area.

2. It can provide data regarding the condition of receptors.

3. It transmits through the spinal cord to the brain.
However, these sensations are not included in the required examinations because the validity of three statements mentioned above is not scientifically proved (7).

Joint Motion and Position Sense (7)

- It is examined from the interphalangeal joint of the thumb; interphalangeal joint of the little finger and wrist; and interphalangeal joint of the toe, ankle, and knee. Either the patient's eyes should be closed or his/her seeing the examined area should be prevented. In the figure, joint motion examination from the interphalangeal joint of the toe is seen (Figure 1). A patient whose sensation is preserved can feel 10 degrees of change. Patient is asked whether the examiner has moved upwards or downwards.

Scoring: (7)

- 0 : Unable to feel even great motions

- 1 : Able to feel only great motions

- 2: Normal

- NT: Not testable (cannot be tested because of various reasons, such as cast and injury)

Deep Pressure (7)

- It can be helpful if no light-touch and pin-pricking sensations exist.

- It can be examined from the wrist radius styloid protrusion, thumb nail bed, little finger nail bed, ankle medial malleolus, toenail bed, and little finger nail bed of the foot.

- The patient's eyes should be closed, or his/her seeing the examined area should be prevented.

- Deep pressure sensation is evaluated by applying pressure on the skin of the various regions of the extremities, wrist, fingers, ankles, and toes for $3-5 \mathrm{~s}$ in patients whose lighttouch and pin-prick sensations have been evaluated as 0 (Figure 2).

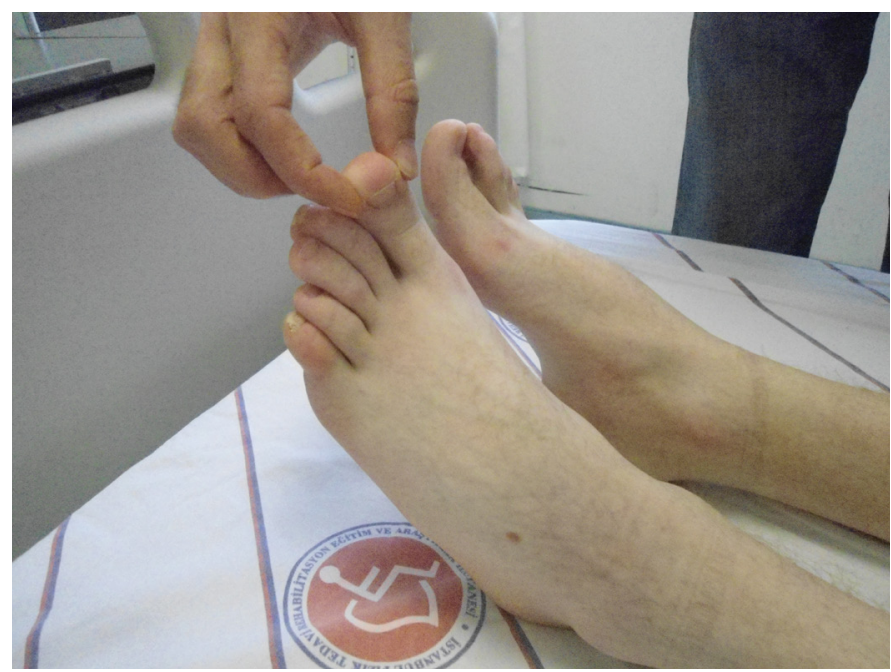

Figure 1. Joint motion and position sensation 


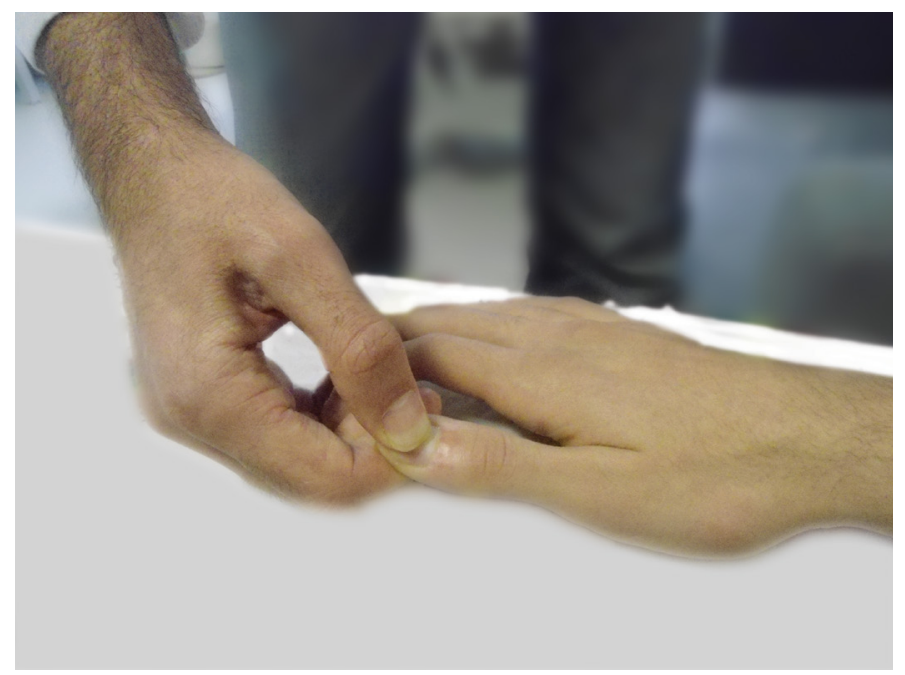

Figure 2. Deep pressure sensation

- As a reference point, the thumb and index finger are pressed on the chin, and it is evaluated as present or absent by comparing with the extremity.

\section{Children}

- Children are not small models of adults. Examination methods change with age.

- Before examination is initiated, both the child and primary caregiver should be well informed regarding the procedure and importance of evaluating light-touch and pin-prick sensations. The physician should sit at the level of the child's height, next to the child. The evaluation should be initiated from light-touch sensation. Then, he/she should describe the procedure by demonstrating it on himself/herself. $\mathrm{He} /$ she gives the child the cotton swap, and the child tries it on both the physician and primary care giver. Similar principles should also be used for pin-pricking sensation; however, the evaluation should begin from the caudal (8).

- Examination methods for the children should be separately learned. Because rehabilitation in children with spinal in- juries is family centered, it is dynamic as the child always grows up and his/her interests continuously change (9).

- Only the main principles of pediatric examination have been mentioned here. For detailed information, the $8^{\text {th }}$ reference can be checked (8).

Peer-review: This manuscript was prepared by the invitation of the Editorial Board and its scientific evaluation was carried out by the Editorial Board.

Acknowledgements: Thanks to Dr. Ahmet Bozan contribution for inspection photos.

Conflict of Interest: No conflict of interest was declared by the author.

Financial Disclosure: The author declared that this study has received no financial support.

\section{References}

1. Kirshblum SC, Burns SP, Biering-Sorensen F, Donovan W, Graves DE, Jha $A$, et al. International standards for neurological classification of spinal cord injury (revised 2011). J Spinal Cord Med 2011;34:53546. [CrossRef]

2. Gündüz B, Erhan B. Omurilik Yaralanması Nörolojik Sınıflaması için Uluslararası Standartlar 2011 Revizyonu: Değerlendirme Formu Türkçe Çevirisi. Turk J Phys Med Rehab 2012;58(Özel Sayı 1);42-5.

3. Gündüz B, Erhan B. Omurga-omurilik yaralanmalarında klinik muayene ve sınıflama. In: Hancı M, Erhan B, editors. Omurga ve Omurilik Yaralanmaları. Inter Tıp. Izmir, 2013. p:207-20.

4. Available from: www.asia-spinalinjury.org/elearning sensory examguide www.asia-spinalinjury.org/elearning- In step sensory modüle 2 .

5. Gündüz B, Erhan B. Omurilik Yaralanması Nörolojik Sınıflaması için Uluslararası Standartlar Değerlendirme Formunun Güncellenmesi. Turk J Phys Med 2015;61:91-4.

6. Oleson CV, Burns AS, Ditunno JF, Geisler FH, Coleman WP. Prognostic value of pinprick preservation in motor complete, sensory incomplete spinal cord injury. Arch Phys Med Rehabil 2005;86:988-92. [CrossRef]

7. Available from: www.asia-spinalinjury.org/elearning- In step optional modüle 6 .

8. Available from: www.asia-spinalinjury.org-Weestep.

9. Gündüz B, Bardak A, Erhan B. Pediyatrik Medulla Spinalis Yaralanması Rehabilitasyonunda Temel İlkeler. Turk J Phys Med 2008;54(Özel Sayı 2);59-61. 